\title{
Research of Manufacturing Quality Technology for the Fourth Generation Nuclear Equipment
}

\author{
Di Zhang ${ }^{1, a}$, Dafeng Ren ${ }^{2, b,{ }^{*}}$ and Xiang Song ${ }^{3, c}$ \\ 1,2,3Shanghai Electric Nuclear Power Group, Shanghai, China \\ azhangdi2@shanghai-electric.com, bzhangdiseu@163.com, c812514881@qq.com \\ *zhangdiseu@163.com
}

\begin{abstract}
Keywords: High temperature gas cooled reactor; Nuclear equipment; Process evaluation; Quality control

Abstract. In this paper, the working principle and the structure of the key equipment of nuclear island were introduced. At the same time, the quality assurance procedures in the processing of equipment parts were studied as well as the methods of welding process evaluation. The constructions and applications of the nuclear grade equipment quality assurance system were researched based on the national nuclear safety regulations, which providing a practical way for the development of safety production quality assurance standards for manufacturing enterprises.
\end{abstract}

\section{Introduction}

Nuclear energy, as a new type of clean energy, has been widely used in electric power, aerospace, medical and health as well as other important areas of the national economy [1]. Nuclear energy was more environment friendly relative to other traditional energy such as coal, natural gas which won't produce soot, sulfur dioxide and nitrogen oxides. At present, the application of nuclear energy was mainly used for power generation by the high heat energy of nuclear fission. In addition, the nuclear power plant covered smaller area, owed higher energy density and was cheaper than hydropower, wind and solar energy. Developing nuclear power had its unique advantages and attractive prospects for the optimization of energy structure, stimulation of regional economic development, improvement of resource utilization, protection of the environment [2].

According to research statistics, the installed capacity of world's nuclear power is expected to grow by $26 \%$ over the next 15 years. By the end of 2030, the total number of nuclear power plants will be increased from about 430 to nearly 500, with a total installed capacity of nearly 500 MW from $370 \mathrm{MW}$. There is about 50 new nuclear power projects currently in China, the construction of 25 units in Haiyang, Sanmen, Taishan, Shidaowan and other places, installed capacity of about 2.7 $\times 107$ kilowatts sixth in the world's the same with India. International advanced states of nuclear power are America (AP1000), France (EPR,), Russia (VVER) and South Korea (APR1400) [2]. At present, the concept of "the fourth generation of advanced nuclear energy system" has been put forward. This nuclear power system has good inherent safety, and will cause less damage to the public when accident occurs. The fourth generation of nuclear high temperature gas cooled reactor (HTR), which designed by Tsinghua University, was one of the most promising technology. The research and development of HTR in China began in the middle of the 70th century. The 10MW capacity HTR was carried out under the support of the national "863" plan and full power grid connected power generation was realized in January 2003. This scientific and technological achievements cause a wide range of influence all over the world [3].

\section{Several development methods of nuclear island equipment}

HTR is a kind of nuclear reactor with high outlet temperature, which using helium as coolant and graphite as moderator. The core temperature of reactor can be up to $1600^{\circ} \mathrm{C}$, the outlet temperature is $850-1000^{\circ} \mathrm{C}$, and even more higher. HTR is famous for its high thermal efficiency $(40 \%-41 \%)$, high fuel consumption, and high conversion ratio $(0.7-0.8)$. Because of the good chemical stability, 
good heat transfer performance, and small induced radioactivity of helium, the waste heat can be brought out, so the safety performance is excellent. In addition, HTR can also provide high temperature heat to manufacture hydrogen, steel, and chemical synthesis [4]. Figure 1 shows the sketch drawing of HTR nuclear island equipment:

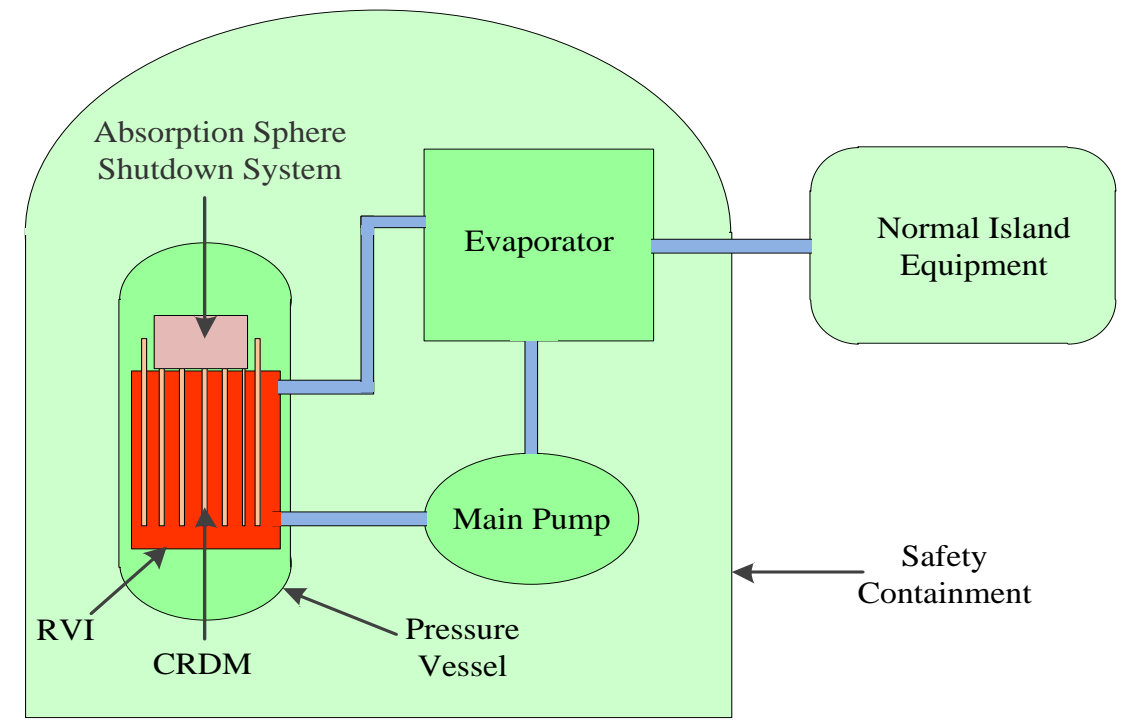

Fig. 1. Sketch drawing of nuclear island main equipment of HTR.

As illustrated in Figure 1, similar to most types of nuclear power stations, the HTR mainly consists of nuclear island equipment and conventional island equipment. Among them, nuclear island equipment consist of RVI (Reactor Vessel Internals), CRDM (Control Rod Drive Mechanism), pressure vessel, evaporator, main pump and so on [4]. RVI and CRDM are the core devices of the reactor, which are used to carry the core fuel, control power and stop the reactor. RVI provides support, neutralization guide steering for the core component and measuring instruments, and guide the coolant inflow and outflow. In addition, RVI can also be used to shield neutron and gamma ray and absorb the impact energy of control rod assembly. In order to make sure the reliable operation of the reactor and implement the requirements of resisting corrosion, working in high pressure and temperature environment, RVI must be very stable. Therefore, the structure of the internal components are very complex as well as large size, high processing accuracy, high manufacturing technology requirements and strict quality assurance. RVI can be divided into several components such as upper supporting structure, lower supporting structure, compression spring, control rod guide tube, internal measurement devices and irradiation monitoring tube. CRDM is used to absorb neutron and then control the reactor rate. In addition to CRDM, the absorption sphere shutdown system can also be used for emergency shutdown by using graphite particles as medium to absorb neutrons, which is a big improvement in HTR relative to other types of reactors.

In order to maintain good performance of nuclear power plant during its design life (40 years), ensure integrity and safety operation of the reactor, it is very important to choose suitable raw materials to manufacture the main equipment. The materials must be corrosion (high stress corrosion, intergranular corrosion and coolant corrosion) resistance, anti-irradiation properties with enough strength and toughness [5]. According to ASME (the American Society of Mechanical Engineers) and RCC-M (French pressurized water reactor nuclear island equipment design and construction rules) requirements, specific material types and characteristics are shown in Table 1 below: 
Table 1. Material types and properties of nuclear equipment.

\begin{tabular}{|c|c|c|c|c|}
\hline Name & Material & Heat treatment & Performance & Use \\
\hline \multirow{6}{*}{$\begin{array}{c}\text { Austenitic } \\
\text { stainless } \\
\text { steel }\end{array}$} & SA-240/304 and304H, plates & Solid solution & \multirow{6}{*}{$\begin{array}{l}\text { Good cold and } \\
\text { hot } \\
\text { workability, } \\
\text { no magnetism, } \\
\text { good } \\
\text { corrosion } \\
\text { resistance }\end{array}$} & \multirow{6}{*}{$\begin{array}{c}\text { Pressure } \\
\text { vessel, RVI }\end{array}$} \\
\hline & SA-182/F304 and F304H, forges & Solid solution & & \\
\hline & SA-336/F304 and F304H, forges & Solid solution & & \\
\hline & SA-479/304、304L and 316, bars & $1 / 8$ hardening & & \\
\hline & SA-213/TP304, tubes & $\begin{array}{l}\text { Quenching and } \\
\text { tempering }\end{array}$ & & \\
\hline & 316L wires & Cold working & & \\
\hline $\begin{array}{c}\text { Martensitic } \\
\text { stainless } \\
\text { steel }\end{array}$ & $403(\mathrm{~N}-4-11)$, forges & $\begin{array}{l}\text { Thermal } \\
\text { annealing }\end{array}$ & $\begin{array}{l}\text { High strength, } \\
\text { corrosion } \\
\text { resistance }\end{array}$ & $\begin{array}{l}\text { Evaporator } \\
\text { and CRDM }\end{array}$ \\
\hline \multirow{2}{*}{$\begin{array}{l}\text { Nickel } \\
\text { alloys }\end{array}$} & SB-166/690 alloys & \multirow{2}{*}{$\begin{array}{l}\text { Hot rolling+ solid } \\
\text { solution }\end{array}$} & \multirow{2}{*}{$\begin{array}{l}\text { oxidation } \\
\text { resistance }\end{array}$} & \multirow{2}{*}{$\begin{array}{c}\text { Steam } \\
\text { generator }\end{array}$} \\
\hline & $\mathrm{X}-750$ alloys & & & \\
\hline
\end{tabular}

According to nuclear safety requirements, structural materials and welding materials must be manufactured by the same material performance and the corresponding qualification of the material manufacturers. And they should do a certain number of systematic experiments to prove to be able to manufacture reactor internal components as well as can be used for the construction if the material manufacturers had no corresponding application performance. Welding is another key and difficult point for design and manufacture devices.

In HTR system, the core barrel of RVI is welded by three circular weld seams of four segment barrels, and the welding quality directly affects the safety and stability of the cylinder and the whole reactor. Welding procedure evaluation should be under the manufacturer's strict supervision and completed by skilled welders of specially welding technology training. Evaluation rules must be prepared according to different types of base metal, welded joints. Types of welding joints and variable parameters must be designed according to different welding method (such as corner welding, butt welding, corrosion resistant coating welding, wear resistant surfacing welding, etc.). Process supervision and verification management system and inspection procedures must be elaborate established in accordance with relevant standards and guidelines.

\section{Nuclear power quality assurance system construction}

In the 70s of last century, scientists of United States put forward the Probabilistic Risk Assessment (PRA) method for nuclear safety research, using the method of probability theory to assess the risks [6]. After several decades of development, the Probabilistic Safety Assessment (PSA) methods is widely used in current domestic nuclear energy field, which was invented by Institute of nuclear energy design and research technology of Tsinghua University. Using fault tree analysis method to calculate the occurrence probability and consequences of all events [7].

During the development process of nuclear equipment, it is necessary to establish strict rules and regulations of the system, and implement high standards of the management models as well as continue to sum up experience, update the design concepts to improve the technical level. Quality assurance system must be in accordance with the rules of Nuclear Power Plant and Other Nuclear Facilities Security Quality Assurance (No. 50-C/SG-Q, 1996) promulgated by International Atomic Energy Agency (IAEA), and meet the regulations of Quality Management System Requirements (ISO9001-2008) promulgated by International Standards Organization (ISO).

It is difficult to avoid all kinds of Non-Conformances (NC) items due to the limitation of the processing technology and various human factors. The Non-Conformance is defined as defects in 
performance, file, or program, which lead to a certain quality of unacceptable affairs or uncertain results. According to research statistics, there are about $350 \mathrm{NC}$ items in all during HTR core devices development progress. Using fault tree of PSA analysis methods as shown in table 2:

Table 2. Analysis and induction of the NC items during HTR development process by using the method of PSA. "P" means Person, "D" means Device and tools, "M" means Material, "T" Means Technology, "E" means Environment.

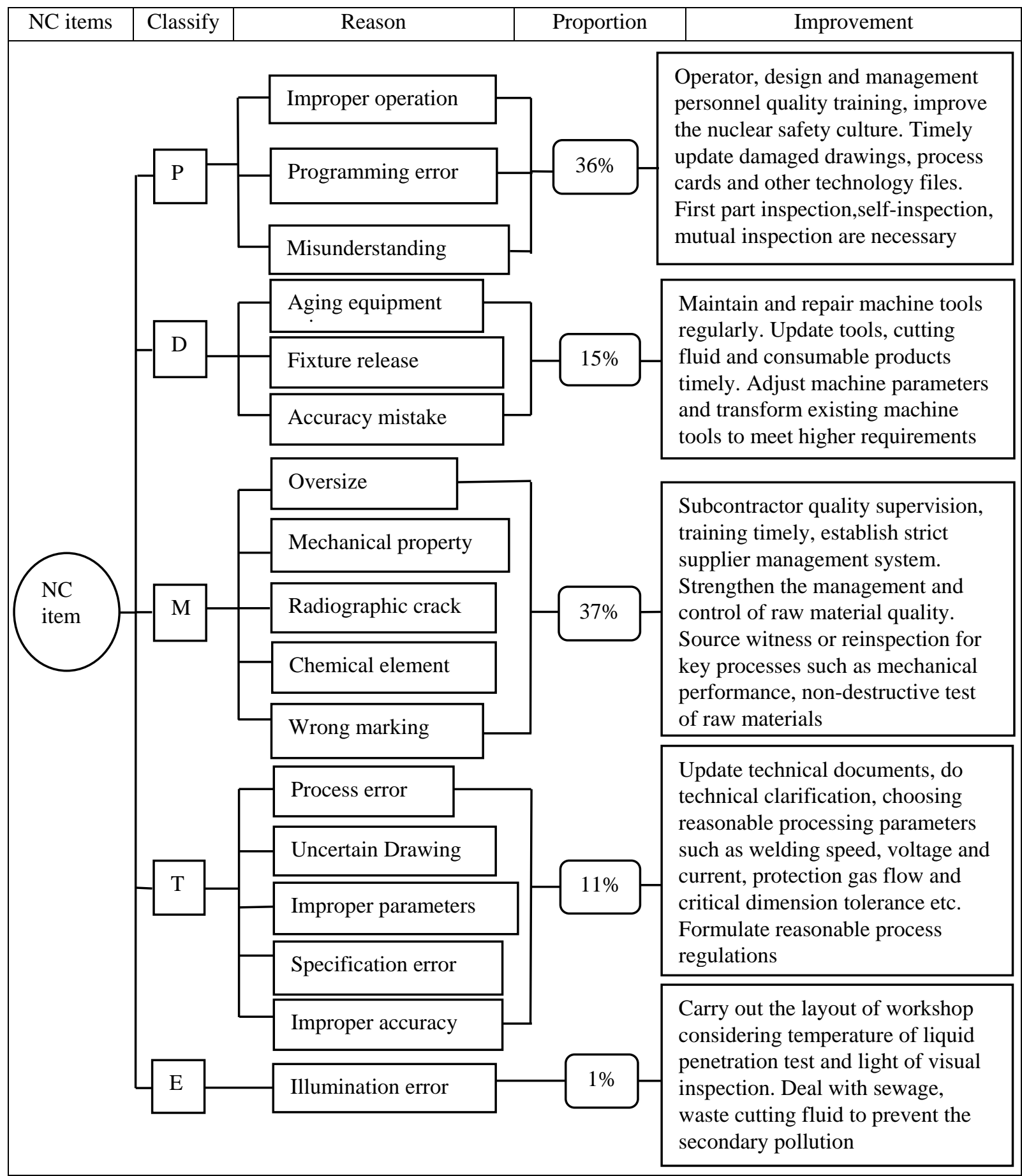

Common types of $\mathrm{NC}$ items are mainly related to the following categories:

a. Raw materials. The content of chemical elements exceed the standard of welding consumables. Mechanical properties of plates, bars of pipes unqualified.

b. Parts machining. This is the most common, frequent defect types of NC items, such as appearance quality, machining dimension, shape and position tolerance, ultrasonic testing, surface roughness, identification of the transplant unqualified, etc.

c. Welding. Such as weld pit, air hole, welding slag, crack, and incomplete fusion, etc. 
d. Assembly. Such as the size of the assembly, clearance deformation unqualified, etc.

e. Process design. Such as drawing size, process card, quality plan, EOMR (End of

Manufacture Report), manufacturing outline and quality assurance procedures unqualified.

Using accident tree to decompose the NC items into tree branch, expand causes and solutions and then draw a picture, so that all key problems are clear. The accident tree of Table 2 shows that "Person", "Material (raw materials)" occupy a large proportion (about $73 \%$ in all) of all NC items. Therefore, from the view of prevention and control methods, it is necessary to carry out nuclear safety culture training and related skills training for relevant personnel before development and manufacture processing of equipment in order to avoid operation mistakes, understanding errors or such issues. Raw material procurement also need to strictly inspection. Especially, important processes such as nondestructive test and mechanical test need to be source witnessed or re-inspection to ensure quality. The fault tree shows majority NC items during HTR equipment manufacture process, in purpose of preventing defects and improving quality through detailed analysis.

\section{Conclusion}

Characteristics of nuclear island main equipment are huge (The height is about 20 meters, and diameter is nearly 6 meters of core barrel of HTR) but precise (Some special tolerance is less than $10^{-3} \mathrm{~mm}$ ), so it's very complex to design and manufacture main devices. Establish corresponding quality assurance system for each project is necessary in order to constraint and guide every activities. Using method of probability theory (PSA) to find out the weak link of system, and then improve the reliability and economy of the quality assurance. It is a wise strategy to develop nuclear power to solve air pollution and resource lack problems.

\section{References}

[1]. S. I. Bhuiyan, Nuclear Power: An Inevitable Option for the Sustainable Development of the Developing Nations to Meet the Energy Challenges of the 21st Century, International Journal of Nuclear Governance Economy and Ecology, 2009.

[2]. Li Weizhe, Wu Xingwei, The Future Development of Nuclear Power in China, Journal of Shenyang Institute of Engineering (Natural Science), 2014.

[3]. Zhang Zuoyi, Wu Zongxin, Design Aspects of the Chinese Modular High-temperature Gas Cooled Reactor HTR-PM, Nuclear Engineering and Design, vol. 236, pp. 485-490, 2006.

[4]. Wu Zhongxin, Zhang Zuoyi, World Development of Nuclear Power System and High Temperature Gas-cooled Reactor, Chinese Journal of Nuclear Science and Engineering, 2000(03).

[5]. Tang Shi, Check and Acceptance about Nuclear Safety Equipment for Civil and Its Welding Materials, Electric Welding Machine, 2010(02).

[6]. Shen Weilan, Probablistic Risk Assessments for PWR Nuclear Power Plants [J], Nuclear Power Engineering, 1985.

[7]. Li Zhaohuan, Some Topics on PSA in Nuclear Power Plant [J], Nuclear Power Engineering, 1990. 